\title{
Congenital fibrosis of superior rectus and superior oblique: a case report
}

\author{
PREM PRAKASH, V MENON, AND G GHOSH \\ From the Dr Rajendra Prasad Centre for Ophthalmic Sciences, All India Institute of Medical Sciences, \\ Ansari Nagar, New Delhi 110029, India
}

SUMMARY A rare case of possible postinflammatory fibrosis of the superior rectus and superior oblique muscles, resulting in marked hypotropia with pseudoptosis, is described, together with the surgical management.

\begin{abstract}
Agenesis or hypoplasia of one or more extraocular muscles has been rather infrequently reported. Absence or hypoplasia of the superior rectus ${ }^{1}$ and inferior rectus ${ }^{2}$ in addition to the horizontal recti has been reported. However, combinations of various muscle anomalies have been less often reportedsuperior and inferior recti, ${ }^{3}$ lateral and inferior recti. ${ }^{4}$ Posey ${ }^{5}$ reported one case of absence of the inferior rectus treated by the Hummelsheim operation. Silverman and Fletcher ${ }^{6}$ reported a case of absence of the inferior oblique and an abnormal insertion of the superior rectus and another case of absent medial rectus and superior oblique with abnormal insertions of other muscles. Starkiewiez ${ }^{7}$ reported a case of absence of the trochlea. Prakash et al. ${ }^{8}$ have reported maldevelopment of the superior oblique and its fascial check mechanism.
\end{abstract}

\section{Case report}

A 7-year-old girl was admitted with a history of downward deviation, ptosis, and defective vision in the right eye since birth. Her birth had been at full term, was normal, and with no history of birth trauma. The mother did not have any illness during pregnancy. All the girl's physical and mental milestones were normal, and she had never had diplopia. She was prescribed glasses a year ago and was referred to us for cosmetic surgery.

General physical examination did not reveal any significant abnormality. Local examination showed slight facial asymmetry, a visual acuity of $1 / 60$ which improved to $3 / 60$ with $+6 \cdot 0 \mathrm{D}$ sph in RE, and $6 / 60$ improving to $6 / 18$ with $+4.5 \mathrm{D}$ sph; $0.5 \mathrm{D} \mathrm{cyl}+90^{\circ}$ in LE.

Correspondence to Dr Prakash.
The right orbit appeared to be set at a lower level than the left. There was ptosis in the RE (Fig. 1). Ocular movement in the RE showed marked restriction of elevation in adduction and abduction and slight restriction of depression in abduction and adduction. A thick fibrous band was felt through the skin of the upper lid, extending as a cord in the upper nasal quadrant between the orbital roof and eyeball. Ocular movements were essentially normal in the left eye.

There was marked hypotropia with exodeviation of the RE. Fixation could not be judged owing to congenital moderate degree of horizontal jerky nystagmus.

Measurements of deviation on synoptophore were as given below:

\begin{tabular}{lll}
\hline$-10^{\circ} \mathrm{L} / \mathrm{R} 44$ & $-15^{\circ} \mathrm{L} / \mathrm{R} 46$ \\
\hline & $-10^{\circ} \mathrm{L} / \mathrm{R} 20$ & \\
\hline$-10^{\circ} \mathrm{L} / \mathrm{R} 10$ & & $-12^{\circ} \mathrm{L} / \mathrm{R} 10$ \\
\hline
\end{tabular}

No binocular functions could be elicited. Fundus examination revealed a hypermetropic appearance with dull foveal reflex in RE. $X$-ray of the orbit and skull did not show any significant abnormality.

The patient was admitted to hospital for cosmetic squint surgery after a forced duction test under general anaesthesia. The forced duction test showed a marked restriction of elevation in adduction and abduction and a moderate restriction of depression in both adduction and abduction.

On exploration it was seen that superior rectus and superior oblique could not be isolated. Instead a firm, thick fibrous band was adherent to the sclera, extend- 
Fig. 1 Before operation. Right hypotropia in primary position with ptosis in RE. There is a marked restriction of right eye on dextroand laevo-elevation.

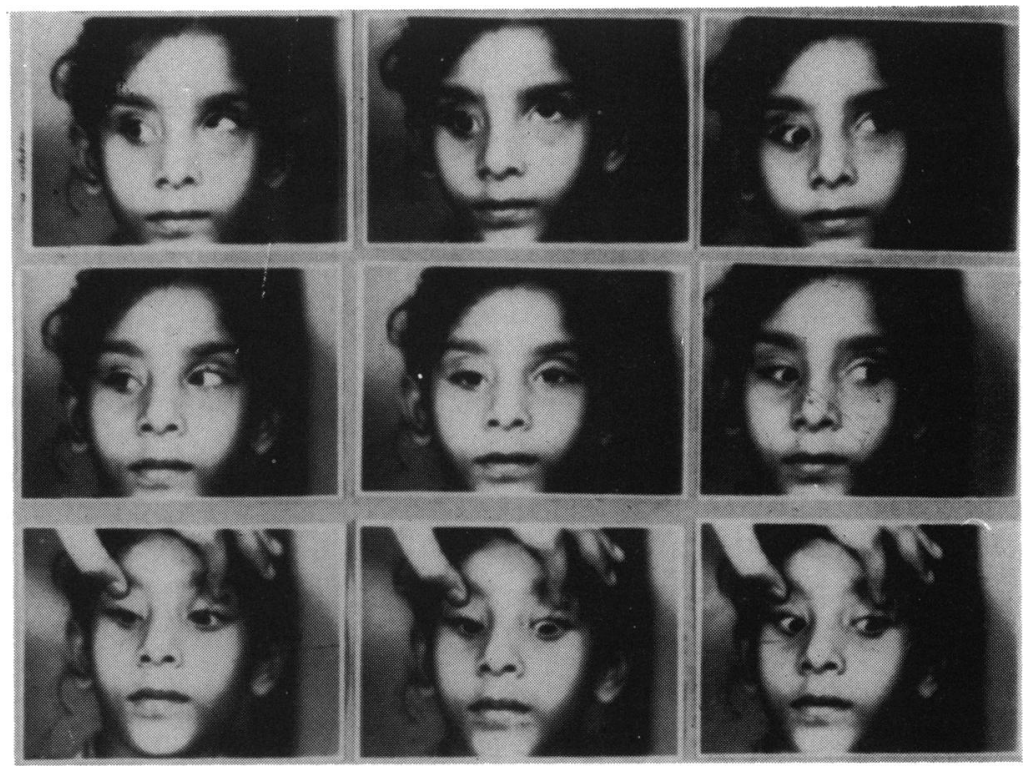

ing upward and nasally towards the trochlea. The anterior limit of this band was $9 \mathrm{~mm}$ on the temporal side and $7 \mathrm{~mm}$ on the nasal side from the limbus (Fig. 2 ). The band was carefully dissected away from the sclera, with resulting free passive movements of the eye ball in all directions. The fibrous tissue was found to be attached to the episcleral tissue and was separated by a careful dissection.

Reassessment after the operation showed almost the same amount of right hypotropia as preoperatively, with the same amount of restriction of 'active movements.' A second operation was therefore undertaken in which Knapp's procedure (transposition of medial and lateral rectus to the superior rectus

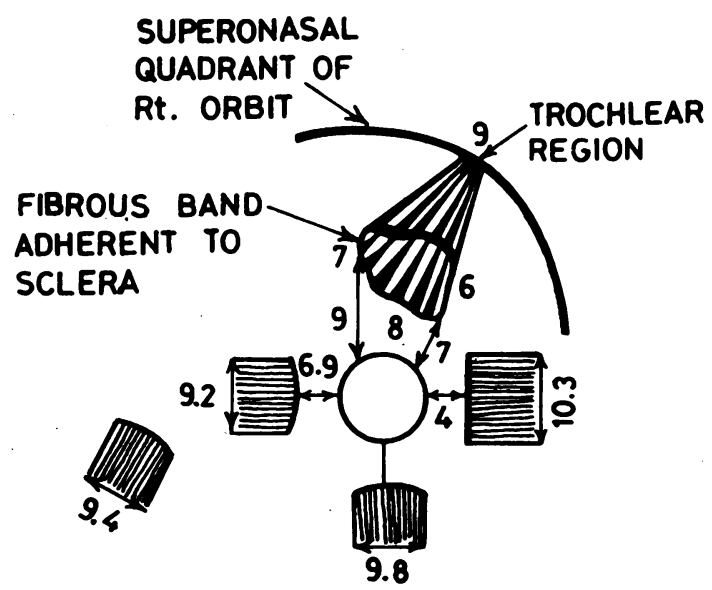

Fig. 2 The area of adherence of the fibrosed band and its possible course. insertion area) was done in the right eye. The medial rectus in the right eye was found to be inserted only $4 \mathrm{~mm}$ away from the limbus. Postoperatively about $10^{\circ}$ of right hypotropia persisted, and the cosmetic appearance was unsatisfactory, especially in elevation. So in a third operation the left superior rectus was recessed by $4 \mathrm{~mm}$ and the left inferior oblique recessed by $8 \mathrm{~mm}$. This resulted in a very satisfactory cosmetic alignment of the eye. The ptosis in the right eye also had corrected itself (Fig. 3).

\section{Discussion}

With the restricted movements in laevo-elevation with the presence of a fibrous band palpable in the upper nasal quadrant of the orbit the case appeared clinically to be an atypical presentation of superior oblique sheath syndrome. However, the restriction of movement in dextro-elevation and dextrodepression did not support this diagnosis. The possibility of a musculofascial anomaly was entertained.

Reports are lacking of any instance of a combined anomaly of the superior oblique and superior rectus in the same eye or even a total absence of the two. As the two muscles develop from different segments of the mesoderm, it is difficult to explain the genesis of this defect. As discussed by Duke-Elder, ${ }^{9}$ there are two main views on the embryological development of the extraocular muscles. According to Lewis ${ }^{10}$ the muscles are developed from a single common premuscle mass, appearing at the $7 \mathrm{~mm}$ embryonic stage, which extends anteriorly and splits into rudiments supplied by 3 cranial nerves at the $10 \mathrm{~mm}$ stage. If this 


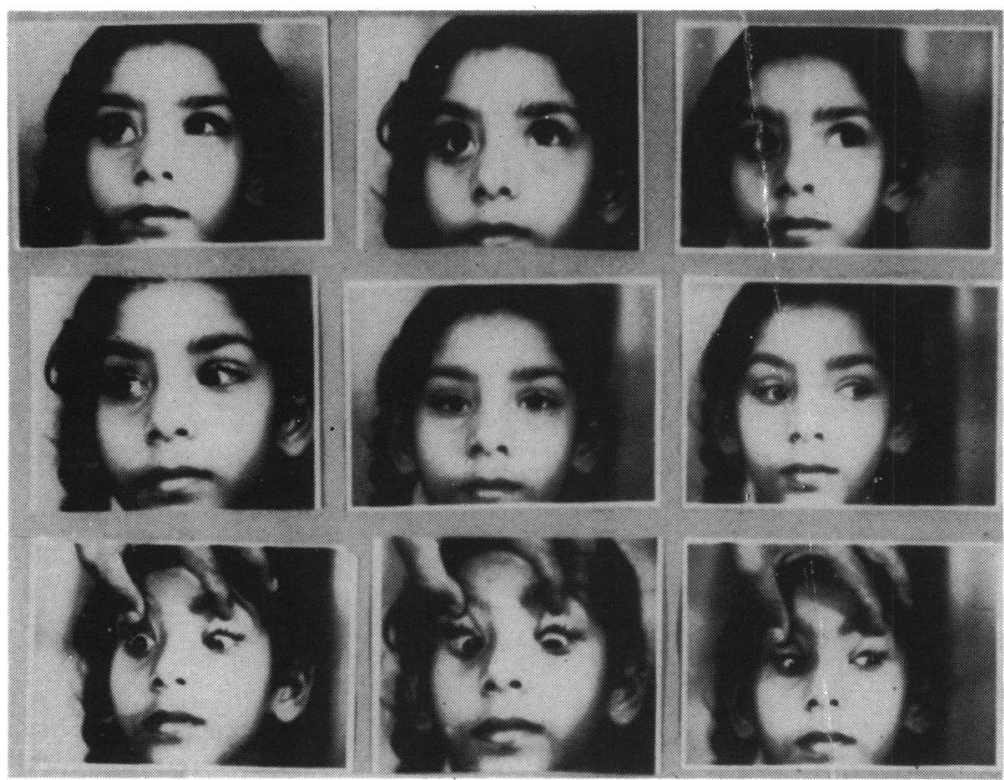

Fig. 3 After thirdoperation. Improvement of ptosis in RE and marked improvement in the cosmetic appearance on elevation ofeye.

is so, any interference with the superior aspects of the globe might hinder the development of the 2 muscles lying there.

But the more generally accepted view is that of Gilbert, " who considers that the extraocular muscles arise from 3 independent but closely related mesodermal condensations supplied by the third nerve from premandibular condensation, and by the fourth and sixth nerves from two separate condensations lying in close contact with the superior rectus anlage. The boundaries of these two muscles become defined only at the $10 \mathrm{~mm}$ stage and start separating from each other. Any hindrance to mesodermal development in this region during these stages may also interfere with the development of the superior rectus and superior oblique.

If we envisage a hindrance to the development at such an early stage, it is inevitable that the levator palprebrae superioris would also be affected. Yet on the contrary it was seen after the three operations and the correction of the hypotropia that the levator was perfectly normal, the ptosis having automatically disappeared. So for the lesion to have involved the superior rectus and superior oblique while sparing the levator it must have occurred after the $55 \mathrm{~mm}$ stage, when the levator had already separated from the superior rectus. Owing to the close proximity of the superior rectus and superior oblique at this insertion it is possible for an intrauterine inflamma- tion to have involved the two muscles. The clinical finding of a fibrous band across the superonasal quadrant of the orbit shows it to be in the region of the superior oblique tendon, which seems to have become involved in postinflammatory fibrosis along with the superior rectus. The anterior limits of the fibrous tissue almost coincided with the insertion of the superior rectus.

\section{References}

1 Steinheim. Klin Monatsbl Augenheilkd 1877; 15: 99. Cited in: Duke-Elder S. System of ophthalmology. London: Kimpton, 1973; 6: 737.

2 Cooper EL, Milk RO, Greenspan JA. Congenital absence of the inferior rectus muscle. Arch Ophthalmol 1971; 86: 451-4.

3 Natale. Arch Oftalmol B Aires 1929; 4: 14.

4 Walker JPS. Congenital absence of inferior and external rectus muscles. Br J Ophthalmol 1954; 38: 631.

5 Posey WC. Anomalies of the eye muscles. Trans Am Acad Ophthalmol Otolaryngol 1924; 28: 243.

6 Silverman SJ, Fletcher MC. Agenesis of three extraocular muscles. A case report. Am J Ophthalmol 1965; 60: 919-22.

7 Starkiewiez. Klin Oczna 1967; 37: 897. Cited in: Duke-Elder S. System of ophthalmology. London: Kimpton, 1973; 6: 737.

8 Prakash P, Diwan C, Khosila PK, Gahlot DK, Tewari HK. Abnormal insertion of superior oblique muscle. East Arch Ophthalmol 1974; 2: 237-40.

9 Duke-Elder S. System of ophthalmology. London: Kimpton, 1963: 3.

10 Lewis WH. In: Keibal F, Hall FB, eds. Manual of embryology. Philadelphia and London: 1912: 2. Cited in: Wolf E. Anatomy of the eye. 7th ed. London: Lewis, 1976.

11 Gilbert PW. The origin and development of the head cavities in the human embryo. J Morphol 1952; 90: 194-8. 